\begin{tabular}{c|c}
\multirow{2}{*}{ EESD'15 } & The $7^{\text {th }}$ International Conference on Engineering Education for Sustainable Development \\
\cline { 2 - 2 } & Vancouver, Canada, June 9 to 12, 2015
\end{tabular}

\title{
SYSTEMS THINKING FOR DEALING WITH WICKED SUSTAINABILITY PROBLEMS: BEYOND FUNCTIONALIST APPROACHES
}

\author{
Johanna Lönngren ${ }^{1,3}$ and Magdalena Svanström ${ }^{2}$ \\ ${ }^{1}$ Department of Applied IT, Chalmers University of Technology, Sweden \\ 2 Department of Chemistry and Chemical Engineering, Chalmers University of Technology, Sweden \\ 3 johanna.lonngren@chalmers.se
}

\begin{abstract}
Many of the most pressing sustainability issues are not purely technical problems. To work for sustainable development (SD) requires addressing wicked sustainability problems (WSPs), such as climate change, poverty, and resource scarcity. Previous research has shown that addressing WSPs is challenging for engineering students. In particular, students may feel overwhelmed by a WSP if they lack appropriate tools for dealing with the complexity, uncertainty, and value conflicts that are present in the situation. In this paper, we aim to investigate whether systems thinking competence (ST) can provide such a tool in engineering education for sustainable development (EESD). For this purpose, we elaborate on previous descriptions of WSPs, and draw on (E)ESD literature about ST to discuss different approaches to ST and their usefulness for addressing WSPs. We conclude that ST indeed can be valuable for addressing WSPs, but that it is necessary to be clear about how ST is defined. We suggest that mainstream approaches to ST in engineering education (EngE) are not sufficient for addressing WSPs.
\end{abstract}

\section{INTRODUCTION}

Many of the most pressing sustainability issues are not purely technical problems. To work for sustainable development (SD) requires addressing highly complex and contested problems, such as climate change, poverty, resource scarcity, environmental degradation, and global health problems. Such problems have been called wicked sustainability problems (WSPs) (Lönngren 2014).

Research on engineering students' approaches towards WSPs indicates that fully integrative approaches to WSPs are most useful for addressing WSPs. Lönngren, Ingerman, and Svanström (forthcoming) have shown that adopting such integrative approaches to WSPs can be challenging for engineering students. Students may feel overwhelmed by a WSP if they lack appropriate tools for dealing with the complexity, uncertainty, and value conflicts that are present in the situation. If students lack such tools, they may understand a problem as a complex system, but still expect to be able to solve it by dividing it into separate parts and solve each of these parts in isolation, i.e. they abandon the systems perspective as soon as they attempt to solve the problem. As students realize that their proposed non-systemic solutions are inappropriate, they may conclude that nothing can be done to improve the situation. Such a conclusion prevents them from further striving to address WSPs.

In this paper, we aim to investigate whether systems thinking competence (ST) can be a valuable tool for facilitating a fully integrative approach to WSPs that takes into account both systemic complexity and the presence of normative conflicts. We focus particularly on the context of engineering education for sustainable development (EESD). For this purpose, we first elaborate previous descriptions of WSPs by contrasting the concept of WSPs to other commonly used terms such as ill-structured problems, wicked 
problems, and design problems. Second, we draw on (E)ESD literature about ST to identify different approaches to ST and discuss their usefulness for addressing WSPs. We conclude that ST indeed can be valuable for addressing WSPs, but that it is necessary to be clear about how ST is defined. We suggest that mainstream approaches to ST that are widely used in engineering education (EngE) (and to some extent in EESD) are not sufficient for addressing WSPs.

\section{WICKED SUSTAINABILITY PROBLEMS}

Jonassen (2000) collected descriptions of a large number of problems from diverse professional, personal, and political contexts. Based on a cognitive task analysis of these problems, Jonassen offers a tentative typology of eleven problem types that are organized along a continuum from well-structured to ill-structured problems. Jonassen further suggests that the more ill-structured a problem is, the more challenging it is to address the problem.

The term ill-structured problems has been used by other scholars to describe problems that involve a high degree of uncertainty (Jonassen 1997); lack definite right or wrong solutions (Voss 1983, Simon 1981, Kitchener 1983, Cho 2002); are highly contextualized (Jonassen 1997); involve political considerations (Fernandes 1999); and are characterized by a high level of inherent ambiguity and normative conflict (King and Kitchener 1994, Jonassen 1997), as well as unclear goals, unstated constraints, and multiple criteria for evaluating solutions (Jonassen 1997, Voss 1987). Unfortunately, despite the widespread use of the term ill-structured problems, connotations associated to the term differ significantly between scholars. In particular, the normative dimension (i.e. the presence of normative conflict) of ill-structured problems is not highlighted by all scholars (e.g. Simon 1973).

Wicked problems is an alternative term that has been widely used in contexts such as design research (e.g. Buchanan 1992) and sustainability research (e.g. Seager, Selinger and Wiek 2012). The term wicked problems was originally introduced by Rittel and Webber (1973) to describe design problems in the domain of social planning, and it explicitly addresses normative dimensions of such problems. Rittel and Webber provided a list of ten characteristics that distinguish wicked problems from what they thought to be the mainstream understanding of problems in domains such as science and engineering:

1. There is no definitive formulation of a wicked problem. [Definitely describing a wicked problem requires that one already knows what the solution will be.]

2. Wicked problems have no stopping rule. [It is always possible to further improve a solution to a wicked problem.]

3. Solutions to wicked problems are not true-or-false, but good-or-bad.

4. There is no immediate and no ultimate test of a solution to a wicked problem. [Because of complex systems interactions, a solution to a wicked problem will have consequences that will reach far into the future and into distant parts of the system. To evaluate a solution to a wicked problem, one would need to wait until all these consequences have occurred.]

5. Every solution to a wicked problem is a "one-shot operation"; because there is no opportunity to learn by trial-and-error, every attempt counts significantly.

6. Wicked problems do not have an enumerable (or an exhaustively describable) set of potential solutions, nor is there a well-described set of permissible operations that may be incorporated into the plan.

7. Every wicked problem is essentially unique. (...) There are no classes of wicked problems in the sense that principles of solution can be developed to fit all members of a class.

8. Every wicked problem can be considered to be a symptom of another problem.

9. The existence of a discrepancy representing a wicked problem can be explained in numerous ways. (...) The analyst's "world view" is the strongest determining factor in explaining a discrepancy and, therefore, in resolving a wicked problem.

10. The planner has no right to be wrong. (...) Planners are liable for the consequences of the actions they generate.

Rittel and Webber 1973, pp.161-167 
Farrell and Hooker argue that Rittel and Webber's description of wicked problems needs to be understood in the historical context in which it was developed:

"At the time of writing, Rittel and Webber were responding specifically to the disappointed expectations aroused by the new systems approaches to problem solving that would bring the social sciences within science and engineering, and more generally to still broader claims for computational approaches to mind and artificial intelligence, engineering and formal management approaches to problem solving, and the like that would permit subsumption of psychology generally (thence economics, etc.) and so also design under the prevailing logical conception of scientific rationality."

Farrell and Hooker 2013, p.682

Farrell and Hooker $(2013,2014)$ argue that since then, much has changed in the understanding of science, engineering and design. Most importantly, science is no longer understood as a purely logical, machine-like activity but a highly contextualized process that results in ever-changing theories with which humans attempt to understand the world. Farrell and Hooker lament that, despite this changing conception of science, design and engineering, the kind of "negative response" that Rittel and Webber offered "to such rationalising ambitions remains widely supported throughout the literature on design process" (Farrell and Hooker 2013, p.682).

In an attempt to disrupt the common understanding of design problems as fundamentally different from science problems, Farrell and Hooker (2013) discuss each of Rittel and Webber's ten characteristics of wicked problems in relation to both design and science problems. They suggest that the ten characteristics can satisfactorily be explained by three general sources of wickedness that are common to design and science: finitude, complexity, and normativity. Finitude is related to the limits of cognitive ability and resources. However smart one is, or however powerful a computer is, there will always be a limit to what processes can be performed. Complexity is described as a result of interactions between parts of systems, such as nested hierarchies, feedback and feedforward loops, or cascading effects in seemingly distant parts of a system. Normativity is related to the importance of human norms and values for problem understanding and resolution. Conflicting norms and values are common between different agents, but even "within an agent's normative commitments" (Farrell and Hooker 2013, p.686).

Farrell and Hooker (2013, p.685) suggest that each of these three sources of wickedness (finitude, complexity, and normativity) represents a methodological challenge for problem resolution. They "content that it is the depth and extent of this methodological challenge that ultimately constitutes the wickedness of a problem". In other words, a problem exhibits a higher degree of wickedness the more finite cognitive resources are, the more complex the problem situation is, and the more important normative aspects are. Farrell and Hooker suggest that there is not a binary demarcation between wicked and non-wicked problems. Rather, there are many kinds of wicked problems, including various kinds of science, engineering and design problems.

In another paper, Farrell and Hooker (2014, p.29) acknowledge that "[d]ifferences continue to exist between design and science in their use of values and norms". While scientists generally "recognise a common set of epistemic values" related to the search for knowledge, "designers face a multitude of client norms that need not be significantly related to one another" (ibid, p.37). In other words, they content that values and norms are more diverse in design than in science.

In the context of SD, values and norms are even more diverse than in many areas of design. While the SD concept introduces some basic constraints (i.e. the necessity to consider ecological, economic, and social aspects for present as well as future generations), we suggest that these constraints increase rather than decrease the potential for value conflicts. For example, the demand to consider future generations means that SD requires designing for resilience rather than measurable performance (Seager, Selinger and Wiek 2012).

Addressing SD problems requires not only considering conflicting interests among a set of clients, it also requires recognizing extended networks of stakeholders that may or may not be able to actively make 
their interests and values known to those who attempt to address a problem (e.g. marginalized groups of humans, non-human animals, ecosystems, or future generations). Issues of justice, power, and agency are central and cannot be reduced to a well-defined set of conflicting values. To denote such problems, we here use the term WSPs (c.f. Lönngren 2014). WSPs should be understood as a subtype of wicked problems that are (a.) guided by a very diverse set of values and norms associated with the concept SD, and (b.) embedded in highly complex, global systems. In other words, WSPs are characterized by exceptionally high levels of complexity and normativity, and thus of wickedness.

We agree with Farrell and Hooker that real-world science and engineering problems often include aspects of finitude, complexity, and normativity, and should therefore be seen as wicked problems. Unfortunately, students in engineering are seldom trained to address wicked problems, let alone WSPs (Jonassen, Strobel and Beng Lee 2006, Seager, Selinger and Wiek 2012). Lönngren, Ingerman, and Svanström (forthcoming) suggest that the current prevalence of well-structured problems in EngE may lead to a lack of awareness of problem types and a false assumption that all kinds of problems can be addressed with the same methodological strategies.

\section{SYSTEMS THINKING COMPETENCE}

ST is widely recognized as an important competency to be developed in the context of education for sustainable development (ESD). Based on a review of the ESD literature on competencies for SD, Wiek, Withycombe, and Redman (2011) suggest that ST is one of five key competencies in ESD (the others being anticipatory competence, normative competence, strategic competence, and interpersonal competence). Wiek et al. offer a definition of ST that has been widely used in the ESD literature (e.g. Claesson and Svanström 2013, Sprain and Timpson 2012):

"Systems-thinking competence is the ability to collectively analyze complex systems across different domains (society, environment, economy, etc.) and across different scales (local to global), thereby considering cascading effects, inertia, feedback loops and other systemic features related to sustainability issues and sustainability problem-solving frameworks" Wiek, Withycombe and Redman 2011, p.207

In this definition, the methodological challenges of dealing with complexity (the presence of a large number of variables, non-linear relationships, etc.) are central. To deal with the exceptionally high level of complexity that is present in sustainability problems, Wiek, Withycombe and Redman (2011) suggest the use of systems analytical methodologies. While normative aspects of sustainability problems, such as "perceptions" and "motives" are mentioned in passing in the above description of ST, Wiek et al. have chosen to mainly describe the challenge of normativity separately as normative competence, which they define as "the ability to collectively map, specify, apply, reconcile, and negotiate sustainability values, principles, goals, and targets" (p.209). We suggest that separating normative competence from ST in this way may lead to an incomplete understanding of ST, in which ST is reduced to a tool for identifying the "current state of the social-ecological system" (p.210), i.e. a form of analytical and descriptive competence. Such an approach to ST could be used if one ensures that it is combined with an analysis of the normative aspects of a situation. However, since ST is more commonly used in EngE than normative competence, and often in a rather instrumental way, we suggest that it is more useful to use an understanding of ST that explicitly includes the challenges of normativity.

Porter and Córdoba draw on literature from systems theory, operations research, and organization theory to develop a framework of three different approaches to ST, particularly in relation to sustainability problems: functionalist, interpretive and complex adaptive systems (CAS) approaches.

Functionalist approaches to systems thinking employ a "scientific, systems analytic perspective" (Porter and Córdoba 2009, p. 328). Such a perspective assumes that systems can be divided into individual components that can be analyzed and optimized independently from each other. The goal of functionalist approaches is to "[calculate] the most efficient and effective solution" (p.326). 
Interpretive approaches employ a more holistic perspective, acknowledging that in complex situations, the whole is greater than the sum of its parts. Systems are seen as "the mental constructs of observers rather than entities with an objective existence" (Porter and Córdoba, p.323). Thus, questions of system definition are a central focus in interpretive approaches. Normative assumptions behind the problem definition are explicitly explored through participative engagement of diverse stakeholders. Despite this focus on diversity, interpretivism assumes "that conflict [among stakeholders] can ultimately be addressed and managed through rational dialogue" (p.337). Thus, "it does not reject the premise that rational, systematic inquiry and insight will eventually yield a workable understanding of any situation" (p.334).

CAS approaches recognize natural systems as not only complex, but also "adaptive". According to Porter and Córdoba, such systems are characterized by self-organization, emergence, and bottom-up change. These characteristics render them "unpredictable and uncontrollable from above" (p.338). CAS approaches recognize that conflicts may be ultimately unresolvable, and that there may not be definite solutions to sustainability problems - or even a "best way of getting things done" (p.338).

\section{SYSTEMS THINKING COMPETENCE AND WICKED SUSTAINABILITY PROBLEMS IN ENGINEERING EDUCATION}

In the previous two sections, we have developed a description of WSPs and summarized different descriptions of ST, respectively. We now return to address the aim of this paper, which is to investigate whether ST can be a valuable tool for facilitating a fully integrative approach to WSPs.

Functionalist approaches to ST take problem definitions and goal formulations for granted. According to Porter and Córdoba, functionalist approaches (such as complex systems analysis) are therefore most useful when problems are easily defined and have clear boundaries, when concrete and predefined goals exist, and when disagreement among stakeholders is low. We suggest that functionalist approaches alone are not suitable for addressing WSPs, since WSPs are characterized by high levels of complexity and normativity. In fact, applying functionalist approaches to WSP may exacerbate rather than reduce existing problems such as power imbalances and environmental degradation.

Interpretive approaches, which include critical approaches, are most useful for understanding the multidimensionality of sustainability problems and the centrality of values and worldviews for problem definition. Porter and Córdoba suggest that interpretive approaches make it possible to take multiple perspectives into account and they may thus help to address social, environmental and economic imbalances. However, interpretive approaches assume that conflicts are ultimately resolvable, which is not the case with regard to WSPs. Lönngren, Ingerman and Svanström (forthcoming) have shown empirically that understanding a WSP as complex and contested while still expecting a definite solution can be associated with a sense of hopelessness which may lead to inaction and thus hamper initiatives for SD. Thus, interpretive approaches, despite their popularity in (E)ESD, may not be sufficient for addressing the complexity and normativity of WSPs.

CAS approaches to ST are useful when the degrees of complexity and conflict in a system are both high, as is the case in WSPs. Porter and Córdoba suggest such problems should be addressed through a combination of all three approaches: "What is possible, and highly valuable, is a toolkit containing all three approaches along with the knowledge of the best use of each" (p.344). Students who know how to use such a toolkit would be able to address complex sustainability problems: "with careful attention to the assumptions and limitations of each approach, the three may be employed simultaneously to address the needs of a single situation" (p.342).

It is important to note that Porter and Córdoba write from the perspective of management education rather than EngE. In EngE, functionalist approaches are often the default, "business-as-usual" mode of addressing problems (Seager, Selinger and Wiek 2012). Engineering students are widely trained to solve "story problems", i.e. purely technical problems that are delivered in short, written stories. All necessary information about a problem is present in the story. To solve story problems, "[l]earners are required to 
identify key words in the story, select the appropriate algorithm and sequence for solving the problem, and apply the algorithm" (Jonassen 2000, p.77). In other words, story problems do not exhibit any of the three sources of wickedness identified by Farroll and Hooker. They resemble neither WSPs (Lönngren, Ingerman and Svanström, forthcoming) nor workplace engineering problems (Jonassen, Strobel and Beng Lee, 2006).

We agree with Farrell and Hooker that addressing complex sustainability problems such as WSPs requires using all tools that are available, i.e. functionalist, interpretive, as well as CAS approaches. Functionalist approaches can be useful for solving limited aspects of a WSP, such as optimizing a specific process that is part of an integrative strategy for addressing a WSP. However, we suggest that the current predominance of functionalist approaches in EngE (which is coupled with the predominance of well-structured problems) is detrimental for the development of students' ability to address WSPs in integrative ways. Therefore, we further suggest that EESD practitioners strive to increase the share of (1.) WSPs rather than story problems, and (2.) interpretive and CAS approaches rather than functionalist approaches to problem solving in their teaching practice. EESD research can support practitioners in this endeavour by further elaborating the descriptions of interpretive and CAS approaches, and investigating the value of such approaches for supporting integrative approaches to WSPs. Research could also provide guidance in the form of intended learning outcomes, assessment approaches, and specific educational activities suitable for developing students' ability to address WSPs in integrative ways.

\section{CONCLUSIONS}

WSPs are problems that are exceptionally complex and characterized by particularly challenging value conflicts. In this paper, we have discussed whether ST can be a valuable tool for facilitating a fully integrative approach to WSPs, particularly in the context of EESD. We have suggested that ST indeed can be valuable for addressing WSPs, but that it is necessary to be clear about what type approach to ST is used (e.g. functionalist, interpretive, CAS) since not all approaches to ST are equally suitable for addressing WSPs. In particular, we have argued that functionalist approaches alone are not sufficient for addressing WSPs. Since functionalist approaches are common in EngE, we have suggested that EESD practitioners should strive to increase the share of (1.) WSPs rather than story problems, and (2.) interpretive and CAS approaches rather than functionalist approaches to problem solving.

\section{References}

Buchanan, R. 1992. Wicked Problems in Design Thinking. Design Issues, 8(2): 5-21.

Cho, K. and Jonassen, D. H. 2002. The Effects of Argumentation Scaffolds on Argumentation and Problem Solving. Educational Technology Research and Development, 50(3): 5-22.

Claesson, A. N. and Svanström, M. 2013. Systems thinking for sustainable development - what does it mean and how is it formed? Engineering Education for Sustainable Development, Cambridge, UK, 2225 September 2013.

Connelly, S. 2007. Mapping Sustainable Development as a Contested Concept. Local Environment: The International Journal of Justice and Sustainability, 12(3): 259-278.

Farrell, R. and Hooker, C. 2013. Design, science and wicked Problems. Design Studies, 34(6): 681-705.

Farrell, R. and Hooker, C. 2014. Values and norms between design and science. Design Issues, 30(3): 29-38.

Fernandes, R. and Simon, H. A. 1999. A study of how individuals solve complex and ill-structured problems. Policy Sciences, 32: 225-245.

Jonassen, D. H. 1997. Instructional Design Models for Well-Structured and III-Structured Problem-Solving Learning Outcomes. Educational Technology Research and Development, 45(1): 65-94.

Jonassen, D. H. 2000. Toward a Design Theory of Problem Solving. Educational Technology and

Research Development, 48(4): 63-85.

Jonassen, D., Strobel, J. and Beng Lee, C. 2006. Everyday Problem Solving in Engineering: Lessons for Engineering Educators. Journal of Engineering Education, 92(2): 139-151.

Kates, R. W., Parris, T. and Leiserowitz, A. A. 2005. What is sustainable development? Environment, Science and Policy for Sustainable Development, 47(3): 8-21. 
King, P. M. and Kitchener, K. S. 1994. Developing Reflective Judgment. San Francisco, CA: JosseyBass.

Kitchener, K. S. 1983. Cognition, Metacognition and Epistemic Cognition: A three-level model of cognitive development. Human Development, 26: 222-232.

Lönngren, J. 2014. Engineering Students' Ways of Relating to Wicked Sustainability Problems. Chalmers University of Technology, Department of Applied IT. Gothenburg: Chalmers.

Lönngren, J., Ingerman, Å. and Svanström, M. (forthcoming). Avoid, Control, Succumb, or Balance: Engineering Students' Conceptions of and Approaches to a Wicked Sustainability Problem.

Porter, T. and Córdoba, J. 2009. Three Views of Systems Theories and their Implications for Sustainability Education. Journal of Management Education, 33(323): 323-347.

Rittel, H. W. and Webber, M. W. 1973. Dilemmas in a General Theory of Planning. Policy Sciences, 4: 155-169.

Seager, T., Selinger, E. and Wiek, A. 2012. Sustainable Engineering Science for Resolving Wicked Problems. Journal of Agricultural Environmental Ethics, 25: 467-484.

Simon, H. A. 1973. The structure of ill-structured problems. Artificial Intelligence, 4:181-201.

Simon, H. A. 1981. The sciences of the artificial (Vol. 2). Cambridge, MA: MIT Press.

Simon, H. A. and Newell, A. 1971. Human Problem Solving: The State of the Theory in 1970. American Psychologist, 26(2): 145-159.

Sprain, L. and Timpson, W. M. 2012. Pedagogy for Sustainability Science: Case-Based Approaches for Interdisciplinary Instruction. Environmental Communication: A Journal of Nature and Culture, 6(4): 532550 .

Voss, J. F. 1987. Learning and Transfer i Subject-Matter Learning: A Problem-Solving Model. International Journal of Educational Research, 11(6): 607-622.

Voss, J. F., Greene, T. R., Post, T. A. and Penner, B. C. 1983. Problem-Solving Skills in the Social Sciences. The Psychology of Learning and Motivation, 17: 165-213

Wiek, A., Withycombe, L. And Redman, L. 2011. Key competencies in sustainability: a reference framework for academic program development. Integrated Research System for Sustainability Science, 6: 203-218. 